\title{
Human Dermal Stem/Progenitor Cell-Derived Conditioned Medium Ameliorates Ultraviolet A-Induced Damage of Normal Human Dermal Fibroblasts
}

\author{
Joong Hyun Shim ${ }^{1}$, Ju-Yearl Park', Mi-Gi Lee ${ }^{2}$, Hak Hee Kang ${ }^{1}$, Tae Ryong Lee ${ }^{1 *}$, Dong Wook Shin ${ }^{1 *}$
}

1 Bioscience Research Institute, Amorepacific Corporation R\&D Center, Yongin-city, Gyeonggi-do, Republic of Korea, 2 Hi-Tech Analysis Team, GyeongGi Bio-Center, GyeongGi Institute of Science \& Technology Promotion, Suwon-city, Gyeonggi-do, Republic of Korea

\begin{abstract}
Adult skin stem cells are considered an attractive cell resource for therapeutic potential in aged skin. We previously reported that multipotent human dermal stem/progenitor cells (hDSPCs) can be enriched from (normal human dermal fibroblasts (NHDFs) using collagen type IV. However, the beneficial effects of hDSPCs on aged skin remain to be elucidated. In the present study, we analyzed the growth factors secreted from hDSPCs in conditioned medium (CM) derived from hDSPCs (hDSPC-CM) and found that hDSPCs secreted higher levels of bFGF, IGFBP-1, IGFBP-2, HGF, VEGF and IGF-1 compared with non-hDSPCs. We then investigated whether hDSPC-CM has an effect on ultraviolet A (UVA)-irradiated NHDFs. Real-time RTPCR analysis revealed that the treatment of UVA-irradiated NHDFs with hDSPC-CM significantly antagonized the UVAinduced up-regulation of the MMP1 and the UVA-induced down-regulation of the collagen types I, IV and V and TIMP1 mRNA expressions. Furthermore, a scratch wound healing assay showed that hDSPC-CM enhanced the migratory properties of UVA-irradiated NHDFs. hDSPC-CM also significantly reduced the number of the early and late apoptotic cell population in UVA-irradiated NHDFs. Taken together, these data suggest that hDSPC-CM can exert some beneficial effects on aged skin and may be used as a therapeutic agent to improve skin regeneration and wound healing.
\end{abstract}

Citation: Shim JH, Park J-Y, Lee M-G, Kang HH, Lee TR, et al. (2013) Human Dermal Stem/Progenitor Cell-Derived Conditioned Medium Ameliorates Ultraviolet AInduced Damage of Normal Human Dermal Fibroblasts. PLoS ONE 8(7): e67604. doi:10.1371/journal.pone.0067604

Editor: Gayle E. Woloschak, Northwestern University Feinberg School of Medicine, United States of America

Received January 9, 2013; Accepted March 7, 2013; Published July 11, 2013

Copyright: ( 2013 Shim et al. This is an open-access article distributed under the terms of the Creative Commons Attribution License, which permits unrestricted use, distribution, and reproduction in any medium, provided the original author and source are credited.

Funding: This study was partly supported by a grant of the Korea Healthcare technology R\&D Project, Ministry of Health \& Welfare, Republic of Korea (Grant No.: A103017). No additional external funding received for this study. The funders had no role in study design, data collection and analysis, decision to publish, or preparation of the manuscript.

Competing Interests: Co-authors Joong Hyun Shim, Ju-Yearl Park, Hak Hee Kang, Tae Ryong Lee and Dong Wook Shin are employed by Amorepacific Corporation R\&D Center. There are no patents, products in development or marketed products to declare. This does not alter the authors' adherence to all the PLOS ONE policies on sharing data and materials.

*E-mail: biopang@amorepacific.com (DWS); TRLee@amorepacific.com (TRL)

\section{Introduction}

Adult stem cells are self-renewable and exist in many adult tissues [1,2]. These cells are attractive, both because of their potential therapeutic use for replacing damaged cells and because they are crucial to understanding how tissues and organs develop. Mesenchymal stem cells (MSCs), a type of adult stem cells, were initially identified from bone marrow [2-4]. MSCs have the potential to differentiate into the mesodermal lineages, such as adipocytes, osteoblasts and chondrocytes, and also non-mesodermal cell types, such as neuronal cells, pancreatic $B$ cells and hepatic cells [2-10]. Several studies have reported that adult dermal stem cells exist in skin dermis and that these cells have properties similar to MSCs [11-22]. These dermal stem cells, which are considered important to maintaining skin homeostasis and for repairing damaged dermis, have been described in rodents and humans. Toma et al demonstrated that these cells, termed SKPs (skin-derived progenitors), are similar to embryonic neural crest stem cells and can differentiate into mesodermal lineage cells, such as adipocytes, osteoblasts and chondrocytes [11,12]. Furthermore, these cells can acquire cell characteristics of nonmesodermal origin, including those of neural cells and hepatic cells. Another study found that multipotent fibroblasts in human dermis can be identified by using a single-cell clonal analysis [16]. Recently, we also reported that human dermal stem/progenitor cells (hDSPCs) from normal human dermal fibroblasts (NHDFs) can be enriched based on the ability to adhere to collagen type IV, which is a binding partner of CD29 [21,22]. We demonstrated that these hDSPCs exhibit increased colony-forming efficiency compared with non -hDSPCs. In addition, we showed that the hDSPCs can differentiate into mesodermal and ectodermal cell types, implying that these cells are multipotent.

Sasaki et al previously showed that the transplantation of MSCs significantly improves wound healing in damaged mouse skin [23]. Other studies demonstrated that wound healing is enhanced when MSCs are administered to humans with acute skin wounds or with chronic skin wounds $[24,25]$. However, in spite of the ability of MSCs to differentiate into specific cell lineages, the low levels of MSC engraftment after transplantation suggested that the beneficial effects of MSCs may be mediated more by their secretion of soluble factors, such as growth factors, than by their long-term presence in damaged tissue [26,27]. A recent report has demonstrated that a conditioned medium culturing murine bone marrow-derived MSCs contains high levels of cytokines and is sufficient to stimulate macrophage and endothelial migration and improve wound healing in Balb/C mice [28]. 
A

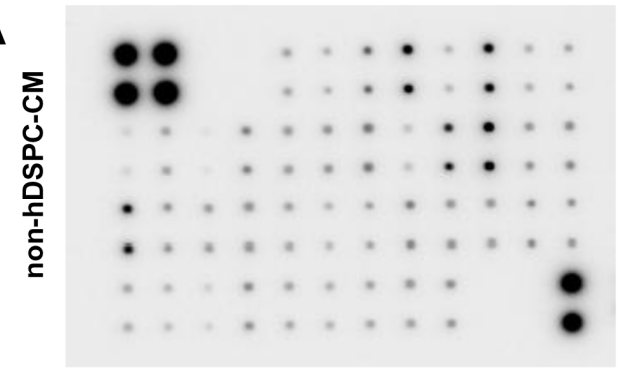

B

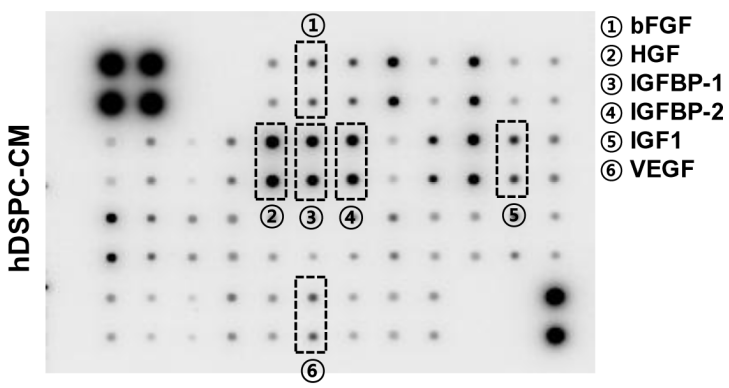

C
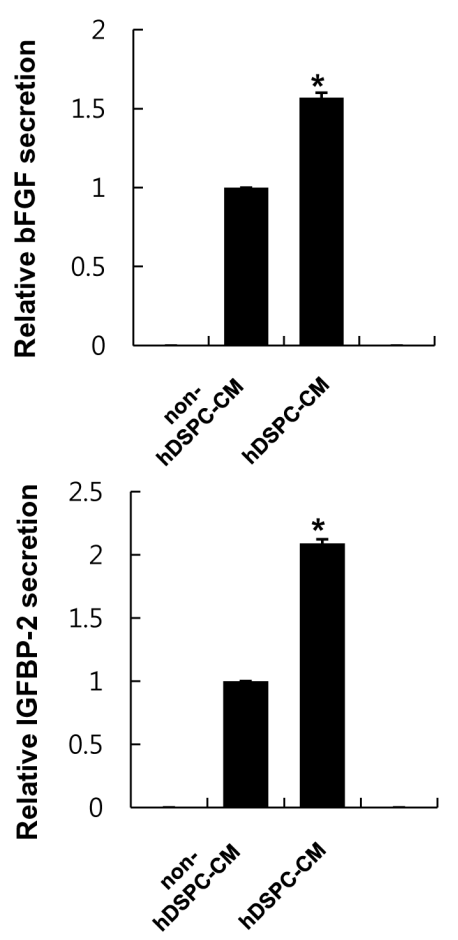
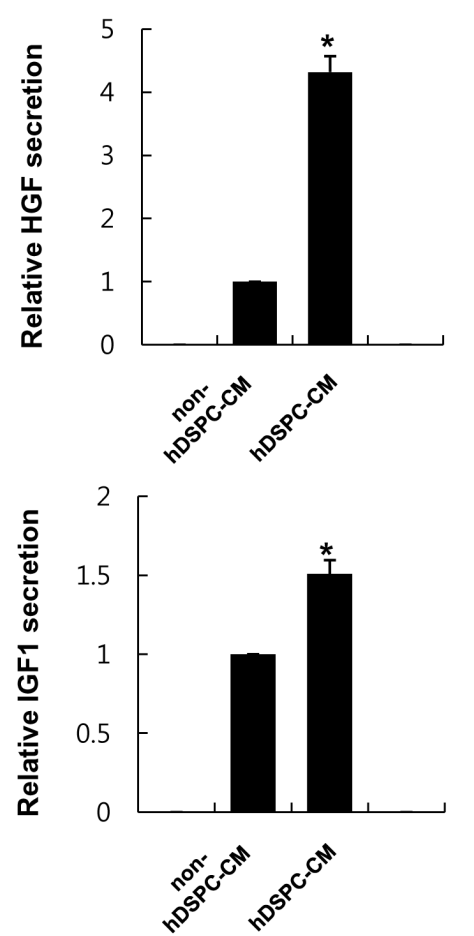
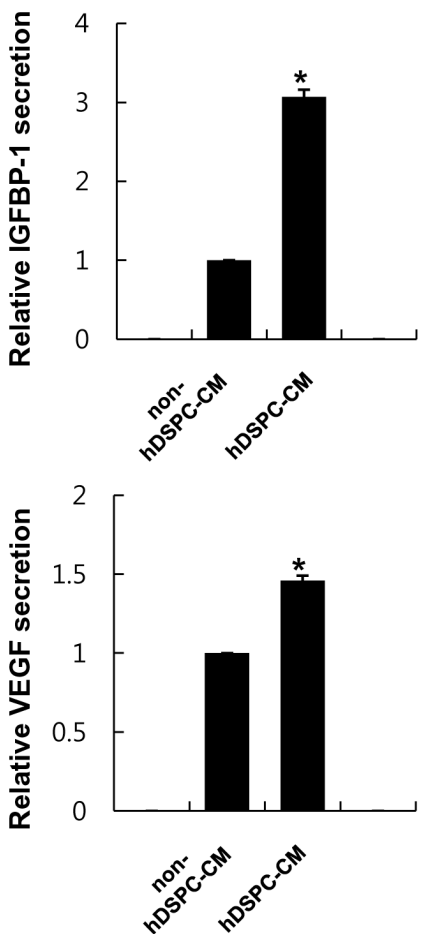

Figure 1. The secretion levels of specific growth factors were increased in hDSPC-CM. Growth factor secretion profiles of non-hDSPC-CM (A) and hDSPC-CM (B) using a human growth factor antibody array, respectively. Relative secretion levels of bFGF, HGF, IGFBP-1, IGFBP-2, IGF1, and VEGF in serum-free hDSPC-CM compared with non-hDSPC-CM (C). The graphs are shown as the mean \pm S.D. of three independent experiments. ${ }^{*} p<0.01$.

doi:10.1371/journal.pone.0067604.g001

We previously suggested the possible use of hDSPCs for acceleration of skin regeneration in aged or damaged skin. However, it is still not known whether hDSPGs can exert their beneficial effects on the regeneration of damaged tissues via paracrine mechanisms involving secretion of soluble factors such as growth factors. Therefore, in the present study, we first compared the levels of paracrine factors secreted from hDSPCs and non-hDSPCs and found that several growth factors, such as IGBP-1 and bFGF, were increased in hDSPC-derived conditioned medium (hDSPC-CM). We then investigated whether hDSPCGM has an influence on UVA-irradiated NHDFs. We found that hDSPC-CM up-regulated the mRNA expression levels of collagen types I, IV and V and TIMP1, which were down-regulated by UVA irradiation and down-regulated the mRNA expression level of MMP1, which was up-regulated by UVA irradiation. We also showed that hDSPC-CM promoted in vitro wound healing of UVA-irradiated NHDFs. In addition, hDSPC-CM significantly decreased the number of UVA irradiation-induced apoptotic cells.
Our results suggest that hDSPC-CM provides another stem cellbased therapeutic potential for curing skin damaged by such harmful agents as UVA irradiation and oxidative stress.

\section{Materials and Methods}

\section{Cell culture of NHDFs and enrichment of hDSPCs}

Normal human dermal fibroblasts (NHDFs, Lonza, Basel, Switzerland) derived from the skin were cultured in DMEM (Lonza) containing 10\% FBS, $100 \mathrm{U} / \mathrm{ml}$ penicillin and $100 \mu \mathrm{g} / \mathrm{ml}$ streptomycin at $37^{\circ} \mathrm{C}$. The NHDFs were used within three passages.

Collagen type IV (Sigma-Aldrich, St. Louis, MO, USA)-coated dishes were prepared by coating 100-mm dishes with collagen type IV $(20 \mu \mathrm{g} / \mathrm{ml})$ overnight at $4^{\circ} \mathrm{C}$. The NHDFs were plated onto the collagen type IV-coated dishes and then sorted on the basis of their ability to adhere to collagen type IV within 5 min (human Dermal Stem/Progenitor Cells; hDSPCs) or within $12 \mathrm{hr}$ (non-hDSPCs) at $37^{\circ} \mathrm{C}[21,22]$. 
Table 1. Relative growth factor secretion analysis of hDSPC-CM.

\begin{tabular}{|c|c|}
\hline Name & Fold change (mean \pm S.D)Ratio: hDSPC/non- hDSPC \\
\hline AR (Amphiregulin) & $1.11 \pm 0.03$ \\
\hline bNGF ( $\beta$-Nerve growth factor) & $1.04 \pm 0.01$ \\
\hline EGF (Epidermal growth factor) & $1.17 \pm 0.01$ \\
\hline EGF-R (Epidermal growth factor-receptor) & $1.07 \pm 0.01$ \\
\hline FGF4 (Fibroblast growth factor 4) & $1.17 \pm 0.01$ \\
\hline FGF6 (Fibroblast growth factor 6) & $1.01 \pm 0.01$ \\
\hline FGF7 (Fibroblast growth factor 7) & $1.04 \pm 0.02$ \\
\hline GCSF (Granulocyte colony stimulating factor) & $1.35 \pm 0.13$ \\
\hline GDNF (Glial cell-derived neurotrophic factor) & $1.2 \pm 0.13$ \\
\hline GM-CSF (Granulocyte-macrophage colony-stimulating factor) & $1.1 \pm 0.05$ \\
\hline HB-EGF (Heparin-binding EGF-like growth factor) & $1.06 \pm 0.01$ \\
\hline IGFBP-3 (Insulin-like growth factor-binding protein-3) & $1.08 \pm 0.03$ \\
\hline IGFBP-4 (Insulin-like growth factor-binding protein-4) & $1.02 \pm 0.02$ \\
\hline IGFBP-6 (Insulin-like growth factor-binding protein-6) & $1.25 \pm 0.06$ \\
\hline IGF-1 SR (Insulin-like growth factor-1 receptor) & $1.07 \pm 0.02$ \\
\hline IGF2 (Insulin-like growth factor2) & $1.26 \pm 0.1$ \\
\hline M-CSF (Macrophage colony stimulating factor) & $1.18 \pm 0.03$ \\
\hline M-CSF R (Macrophage colony stimulating factor receptor) & $1.03 \pm 0.02$ \\
\hline NT-3 (Neurotrohpin-3) & $0.99 \pm 0.04$ \\
\hline NT-4 (Neurotrohpin-4) & $1.03 \pm 0.05$ \\
\hline PDGF R $\alpha$ (Platelet derived growth factor receptor $\alpha$ ) & $1.07 \pm 0.05$ \\
\hline PDGF R $\beta$ (Platelet derived growth factor receptor $\beta$ ) & $1.07 \pm 0.07$ \\
\hline PDGF-AA (Platelet derived growth factor-AA) & $1.01 \pm 0.03$ \\
\hline PDGF-AB (Platelet derived growth factor-AB) & $0.91 \pm 0.06$ \\
\hline PDGF-BB (Platelet derived growth factor-BB) & $0.92 \pm 0.01$ \\
\hline PIGF (Placental growth factor) & $1.1 \pm 0.04$ \\
\hline SCF (Stem cell factor) & $0.93 \pm 0.01$ \\
\hline SCF R (Stem cell factor receptor) & $1.04 \pm 0.06$ \\
\hline TGF- $\alpha$ (Transforming growth factor- $\alpha$ ) & $0.94 \pm 0.02$ \\
\hline TGF- $\beta$ (Transforming growth factor- $\beta$ ) & $0.94 \pm 0.01$ \\
\hline TGF- $\beta 2$ (Transforming growth factor- $\beta 2$ ) & $0.98 \pm 0.05$ \\
\hline TGF- $\beta 3$ (Transforming growth factor- $\beta 3$ ) & $0.99 \pm 0.01$ \\
\hline VEGF R2 (Vascular endothelial growth factor receptor2) & $0.96 \pm 0.04$ \\
\hline VEGF R3 (Vascular endothelial growth factor receptor3) & $0.95 \pm 0.07$ \\
\hline VEGF-D (Vascular endothelial growth factor-D) & $0.95 \pm 0.03$ \\
\hline
\end{tabular}

\section{Preparation of hDSPC-CM}

hDSPCs $\left(1 \times 10^{5}\right.$ cells $\left./ \mathrm{ml}\right)$ were cultured in DMEM (Lonza) serum-free medium. The conditioned medium $(\mathrm{CM})$ was collected after $48 \mathrm{hr}$ of suspension culture in Hydrocell ${ }^{\mathrm{TM}}$ dishes (Nunc, Paisley, UK), centrifuged at $300 \times g$ for $5 \mathrm{~min}$ and filtered through a $0.22-\mu \mathrm{m}$ syringe filter (Millipore, Billerica, MA, USA).

\section{Ultraviolet $A$ irradiation}

Before UVA exposure, the NHDFs were washed with PBS and protected from drying by adding DMEM (Phenol red-free, Lonza) at $0.1 \mathrm{ml} / \mathrm{cm}^{2}$. UVA irradiation was performed using BIO-SUN (Vilber Lourmat, Torcy, France). Immediately after the UVA irradiation, the DMEM was aspirated and replaced with the conditioned medium. UVA irradiation doses were tested from 4 to $10 \mathrm{~J} / \mathrm{cm}^{2}$, and $6 \mathrm{~J} / \mathrm{cm}^{2}$ was used in the ensuing experiments.

\section{Cell proliferation assay}

The NHDFs were plated at a density of $2 \times 10^{5}$ cells/well in 6well plates, and the proliferation of the NHDFs was measured using a CGK-8 assay (Dojindo, Rockville, MD, USA). After UVA irradiation, the cells were continuously cultured for $48 \mathrm{hr}$ under each condition. CCK-8 solution $(10 \mu \mathrm{l})$ was added to the cells in $1 \mathrm{ml}$ DMEM and incubated for $1 \mathrm{hr}$ at $37^{\circ} \mathrm{C}$; the absorbance was then measured at $450 \mathrm{~nm}$ using a SpectraMax 190 microplate reader (Molecular Devices, Sunnyvale, CA, USA). 
A

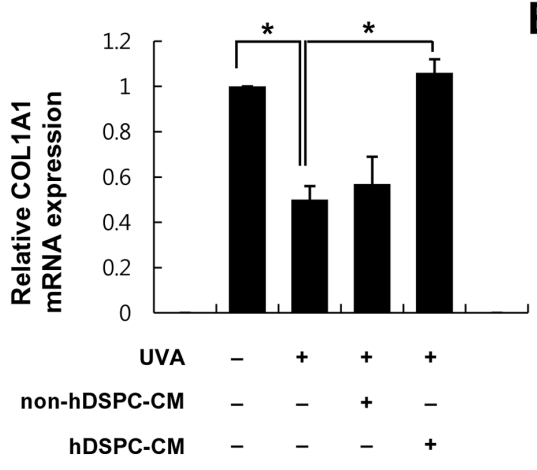

B

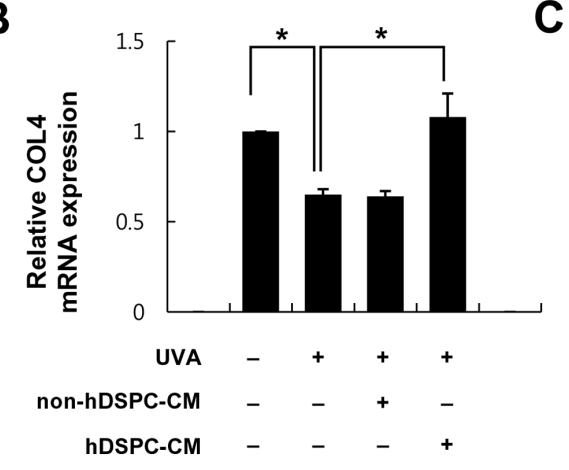

E

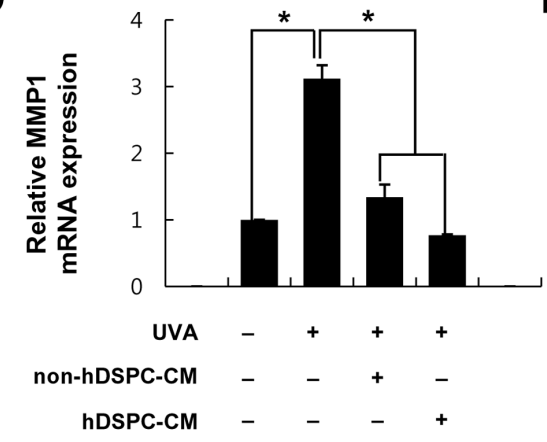

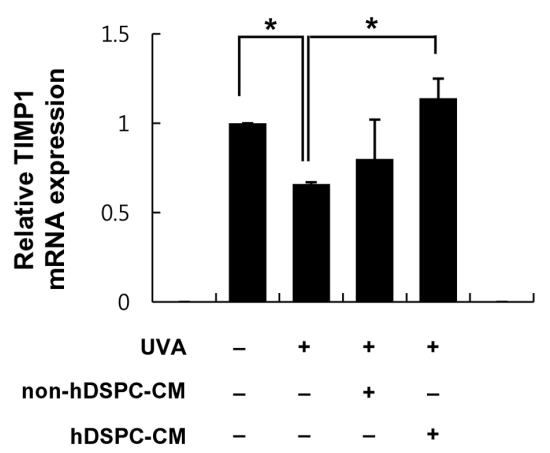

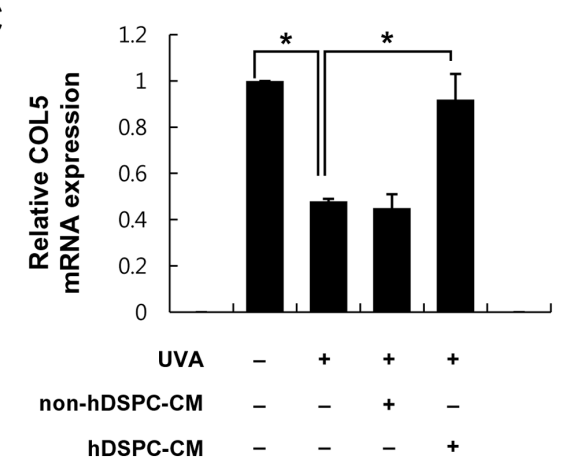

Figure 2. hDSPC-CM restored the down-regulated mRNA expressions of specific dermal makers in UVA-irradiated NHDFs. NHDFs were irradiated with UVA $\left(6 \mathrm{~J} / \mathrm{cm}^{2}\right)$ and treated with either hDSPC-CM or non-hDSPC-CM for $24 \mathrm{hr}$. Total RNA was extracted, and real-time RT-PCR was performed for $\operatorname{COL1A} 1(A), \operatorname{COL} 4 \mathrm{~A} 1(\mathrm{~B}), \operatorname{COL} 5 \mathrm{~A} 1(\mathrm{C}), \mathrm{MMP} 1(\mathrm{D})$, and TIMP1(E). The graphs are shown as the mean \pm S.D. of three independent experiments. ${ }^{*} p<0.01$

doi:10.1371/journal.pone.0067604.g002

\section{RNA isolation and real-time RT-PCR}

Total RNA was extracted with TRIzol (Invitrogen, Carlsbad, CA, USA), and the RNA concentration was determined using a NanoDrop spectrophotometer (Thermo Scientific, Fremont, CA, USA). To produce cDNA, $2 \mu \mathrm{g}$ of RNA was reverse-transcribed using ReverTra Ace reverse transcriptase (Toyobo, Osaka, Japan); the reverse transcription was stopped by adding Tris-EDTA buffer $(\mathrm{pH} 8.0)$ to a total volume of $100 \mu \mathrm{l}$. Real-time RT-PCR was performed according to the manufacturer's instructions. Briefly, each $20 \mu \mathrm{l}$ PCR mixture contained $10 \mu \mathrm{l} 2 \times$ TaqMan ${ }^{\circledR}$ universal PCR Master Mix, $1 \mu \mathrm{l} 20 \times$ of TaqMan ${ }^{\circledR}$ Gene Expression assay, and $50 \mathrm{ng}$ cDNA. Real-time RT-PCR was performed using a 7500 Fast Real-Time PCR System (Applied Biosystems, Foster city, CA, USA). The TaqMan ${ }^{\circledR}$ Gene Expression Assay was purchased from Applied Biosystems. The cDNA samples were analyzed to determine the expression of the following: COL1A1, Hs00164004_ml; COL4Al, Hs00266237_ml; COL5Al, Hs00609088_ml; MMP1, Hs00899658_ml; and TIMP1, Hs00171558_ml. Human GAPDH (43333764F) (Applied Biosystems) was used for normalizing the variation in the cDNA quantities from different samples.

\section{Detection of apoptosis}

To stain apoptotic cells, the cells were washed twice with PBS and then once with Annexin $\mathrm{V}$ binding buffer (BD Pharmingen, San Jose, CA, USA). The cells were stained for $15 \mathrm{~min}$ with Annexin V-FITC (BD Pharmingen). After washing with Annexin binding buffer, the slides were mounted in binding buffer. The cells were examined using an EVOS fl fluorescence microscope (Advanced Microscopy Group, Mill Creek, WA, USA).

An analysis of apoptosis was also performed using an Annexin V-FITC apoptosis detection kit I (BD Pharmingen) with flow cytometry. Briefly, the cells were harvested $24 \mathrm{hr}$ after culturing with hDSPC-CM, washed with PBS, and stained with Annexin VFITC and propidium iodide (PI) for $15 \mathrm{~min}$ at RT in the dark. Flow cytometry was performed using FACSAria II (Becton Dickinson, San Jose, CA, USA). The data analyses were performed using FACSDiva software.

\section{Scratch wound healing assay}

NHDFs were seeded in 6-well plates at a density of $2 \times 10^{5}$ cells/ well in DMEM containing 10\% FBS and cultured until 80 90\% confluence. The NHDFs were irradiated with UVA and then scraped with a 5 -ml pipette tip to generate scratch wounds; the cells were washed twice with serum free-DMEM to remove cell debris. The cells were then incubated at $37^{\circ} \mathrm{C}$ for $48 \mathrm{hr}$ with the conditioned medium. To record scratch wound closure, images were captured at 0,24 , and $48 \mathrm{hr}$ time points in the same position using an Olympus IX71 microscope (Olympus, Southborough, MA, USA). To assess wound closure, the wound perimeter under each condition was traced. Each time point was normalized to the post-scratch day 0 image area and reported as the percent area closed. 

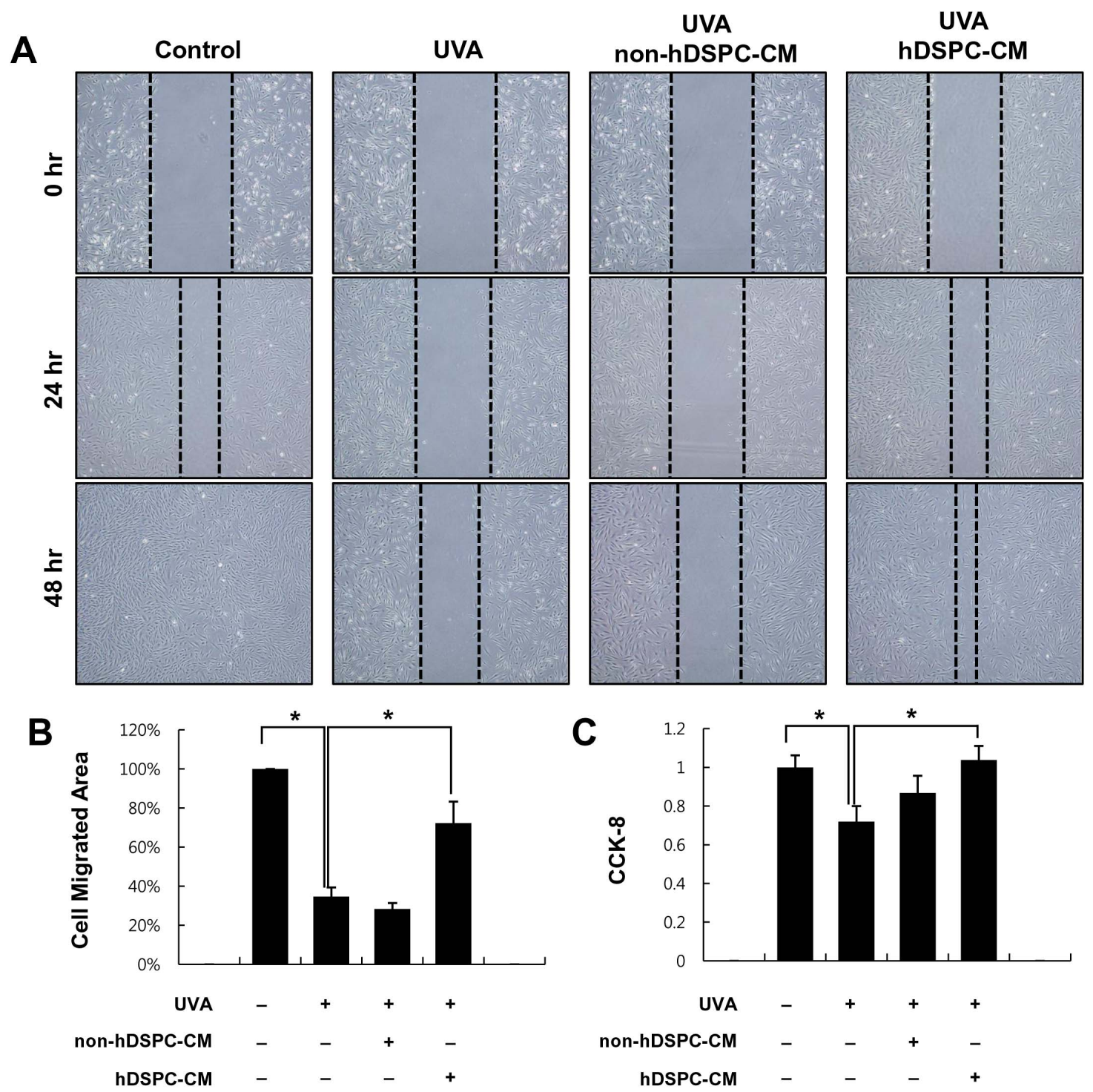

Figure 3. hDSPC-CM promoted the migration and proliferation of UVA-irradiated NHDFs. Effects of hDSPC-CM on NHDF migration. Scratch wound healing assays were performed using conditioned media and UVA-irradiated NHDFs for $48 \mathrm{hr}$. Images were obtained at 0,24 , and $48 \mathrm{hr}$ (A). Quantitative analysis of the scratch wound healing assay after $48 \mathrm{hr}$ (B). The proliferation of the NHDFs was examined in the presence or absence of hDSPC-CM or non-hDSPC-CM. CCK-8 assay was performed at $48 \mathrm{hr}$ (C). The graphs are shown as the mean \pm S.D. of three independent experiments. ${ }^{*} p<0.01$

doi:10.1371/journal.pone.0067604.g003

\section{Human growth factor/cytokine antibody array}

The Raybio ${ }^{\circledR}$ Human Cytokine/Growth Factor Antibody array I (RayBiotech, Noncross, GA, USA) was used to assay over 23 cytokines/41 growth factors in the supernatants of sorted cell cultures. The array membranes were incubated in blocking buffer for $30 \mathrm{~min}$ at room temperature (RT), and $1 \mathrm{ml}$ of the conditioned medium was added per well, followed by incubation for $1 \mathrm{hr}$ at RT. The membranes were washed five times in wash buffer at RT, and a biotin-conjugated antibody was added for $1-2 \mathrm{hr}$ at RT. The membranes were washed again, and $2 \mathrm{ml}$ of HRP-conjugated streptavidin was added for $2 \mathrm{hr}$, followed by the addition of detection buffer for $2 \mathrm{~min}$. The membranes were then detected using the LAS 3000 chemiluminescence imaging system (Fujifilm Inc., Tokyo, Japan).

\section{Statistical analysis}

The statistical analyses of the data were performed using a oneway analysis of variance (ANOVA). The results are expressed as the mean \pm standard deviation of at least three independent experiments, and $p<0.05$ was considered significant.

\section{Results}

Profiles of growth factors/cytokines secreted from hDSPCs

According to previous reports [26-28], several types of mesenchymal stem cells, including adipose-derived stem cells, secrete a variety of growth factors and cytokines into their medium (conditioned medium). Thus, we examined the profiles of growth factors and cytokines secreted from hDSPCs using a human cytokine/growth factor antibody array. The results showed that 
A
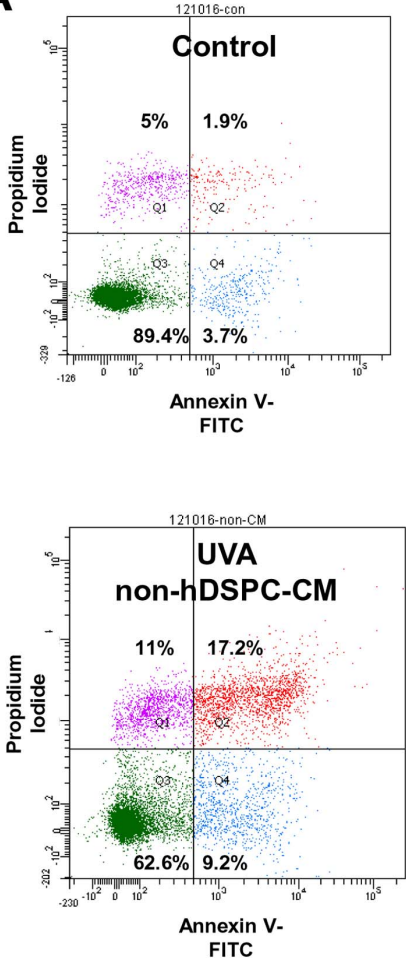

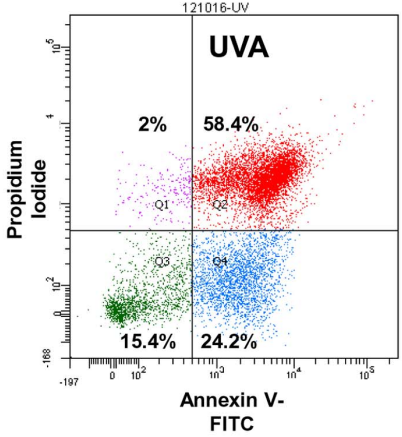

FITC

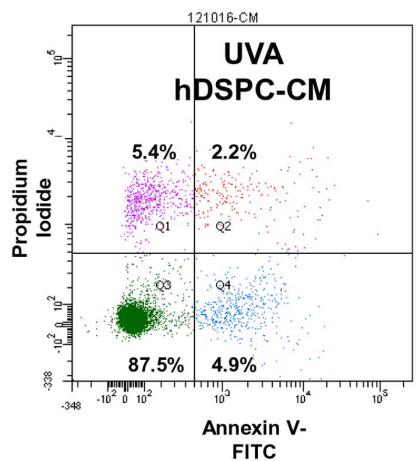

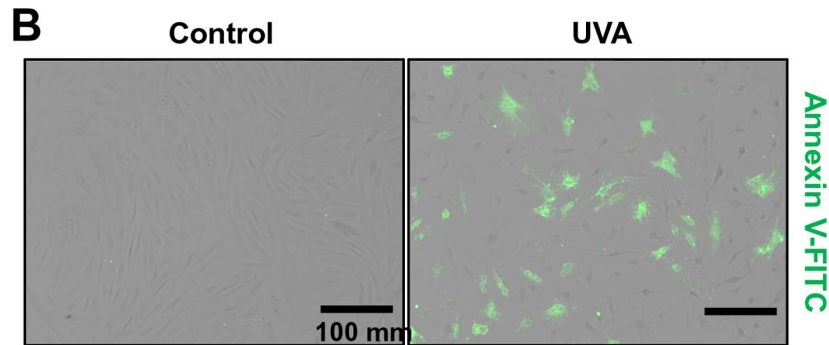

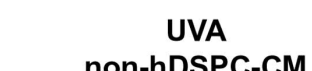

UVA

hDSPC-CM

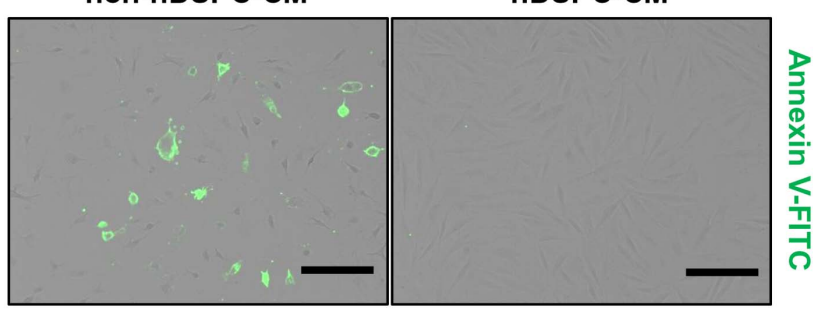

Figure 4. UVA irradiation-induced apoptotic cells were recovered by hDSPC-CM. NHDFs were irradiated with UVA $\left(6 \mathrm{~J} / \mathrm{cm}^{2}\right)$ and incubated with either hDSPC-CM or non-hDSPC-CM for $24 \mathrm{hr}$ and labeled with Annexin V-FITC and propidium iodide (PI). The distribution of apoptotic cells was analyzed using FACSAria II instrumentation. Only PI positive cells are dead (Q1). Cells showing Annexin V and PI double-labeling represent the stage of late apoptosis (Q2). Live cells were not labeled with Annexin V and PI (Q3), whereas Annexin V-labeled cells (Q4) represent the early stage of apoptosis. Ten thousand cells were analyzed for each condition (A). Apoptotic cells labeled with Annexin $V$ under fluorescence microscopy to examine the effects of hDSPC-CM (B). The data are representative of three independent experiments.

doi:10.1371/journal.pone.0067604.g004

hDSPCs secreted relatively higher levels of bFGF $(1.56 \pm 0.03)$,

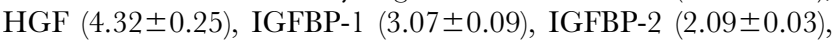
IGF-1 (1.51 \pm 0.09$)$, and VEGF $(1.46 \pm 0.03)$ compared with nonhDSPCs $(p<0.01)$ (Fig. 1, Table 1). However, we found that the hDSPCs showed no significant differences in their secretion level of such cytokines as IL- $1 \alpha$ and IL- 8 compared with the nonhDSPGs (Table S1).

\section{Effects of hDSPC-CM on the mRNA expression levels of NHDF specific markers}

We next investigated whether hDSPG-CM or non-hDSPC-CM could restore the disturbed mRNA expression of NHDF specific markers in UVA-irradiated NHDFs. UVA irradiation $\left(6 \mathrm{~J} / \mathrm{cm}^{2}\right)$ decreased the mRNA expression levels of collagen types I $(0.5 \pm 0.06)$, IV $(0.65 \pm 0.03)$, and $\mathrm{V}(0.48 \pm 0.01)$ and TIMP1 $(0.66 \pm 0.01)$ (Fig. $2 \mathrm{~A}-2 \mathrm{C}, 2 \mathrm{E}$ ), which are among the most important components in skin dermis. Conversely, UVA irradiation increased the mRNA expression level of MMP 1 (3.12 \pm 0.2$)$ $(p<0.01)$ (Fig. 2D). Interestingly, both hDSPG-CM and nonhDSPC-CM significantly reduced the UVA-induced increase of MMP1 gene expression (Fig. 2D), whereas only hDSPC-CM significantly restored the down-regulated mRNA expression levels

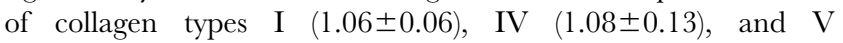
$(0.92 \pm 0.11)$ and TIMP1 $(1.14 \pm 0.11)$ by UVA irradiation (Fig. 2A-2C, 2E).

\section{Effects of hDSPC-CM on the wound healing process}

To investigate whether hDSPC-CM has an effect on the migration of NHDFs irradiated with UVA $\left(6 \mathrm{~J} / \mathrm{cm}^{2}\right)$, a scratch wound healing assay was performed. The data showed that the UVA-irradiated NHDFs exhibited significantly slower repair of scratch wounds compared with the control NHDFs (Fig. 3A, 3B). Although non-hDSPC-CM had no effect on the migration of UVA-irradiated NHDFs, hDSPC-CM significantly increased the migration of UVA-irradiated NHDFs, indicating that hDSPC-CM could improve the reduced migration of NHDFs irradiated with UVA (Fig. 3A, 3B). In addition, a CCK8 analysis also revealed that hDSPC-CM-treated NHDFs showed more recovery of reduced proliferation by UVA irradiation than non-hDSPCCM-treated NHDFs, data that are consistent with the data from the scratch wound healing assay (Fig. 3C).

\section{Effects of hDSPC-CM on apoptotic NHDFs irradiated with UVA}

FACS analyses were performed to estimate the effects of hDSPC-CM on the apoptotic cell death of the UVA-irradiated NHDFs. NHDFs were exposed to UVA at a dose of $6 \mathrm{~J} / \mathrm{cm}^{2}$, incubated with hDSPC-CM or non-hDSPC-CM for $24 \mathrm{hr}$, and labeled with Annexin V-FITC and propidium iodide (PI). The FACS analysis revealed that, after UVA exposure, $24.2 \%$ of the UVA-irradiated cells (Annexin V-positive/PI-negative; Q4 region) were in the early apoptotic stage, which was significantly reduced to $4.9 \%$ in the hDSPC-CM-treated cells, similar to $3.7 \%$ for the control (Fig. 4A). The number of double-stained cells in the late 
stage of apoptosis (Annexin V-positive/PI-positive; Q2 region) was also significantly decreased in the hDSPC-CM-treated cells, from $58.4 \%$ to $2.2 \%$ compared with $17.2 \%$ for the non-hDSPG-CMtreated cells (Fig. 4A). The unlabeled cells, representing the live population (Annexin V-negative/PI-negative; Q3 region), were markedly increased in the hDSPC-CM-treated cells, from $15.4 \%$ to $87.5 \%$, compared with $62.6 \%$ for the non-hDSPC-CM-treated cells (Fig. 4A). The fluorescent microscope images also showed that hDSPC-CM decreased the number of UVA-induced apoptotic cells, which were stained with Annexin V-FITC, compared with non-hDSPG-CM, data that were in accordance with the FACS analysis (Fig. 4B).

\section{Discussion}

In the present study, we demonstrated that hDSPC-CM has several beneficial effects on NHDFs damaged by UVA irradiation. First, a real-time RT-PCR analysis revealed that hDSPC-CM restored the UVA-induced decrease of representative dermal markers, such as collagen types I, IV, and V and TIMP1, but also attenuated the UVA-induced increase of MMP1 in NHDFs (Fig. 2). Second, an in vitro scratch wound healing assay showed that hDSPC-CM enhanced the rate of wound closure in NHDFs irradiated with UVA compared with non-hDSPC-CM (Fig. 3). Third, the FACS analysis indicated that hDSPG-CM significantly decreased the number of NHDFs undergoing apoptotic cell death by UVA irradiation (Fig. 4).

Furthermore, when we applied the hDSPC-CM to NHDFs without UVA irradiation, we found that hDSPG-CM had no effects on expression levels of representative dermal markers (Fig. S1), migration (Fig. S2), the population of apoptotic cells (Fig. S3), and except for reduction of reactive oxygen species (ROS) level immediately after the treatment (Fig. S4), indicating that it is not easy to see the effects of hDSPC-CM on normal cells, although the hDSPC-CM has some helpful effects for the recovery of damaged cells.

The aging process causes a gradual decrease in the maintenance of both homeostasis and the regenerative properties of all tissues and organs [29-32]. In particular, upon skin aging through such processes as photoaging and intrinsic aging, the elasticity of skin is significantly reduced, the wrinkles in the human face gradually become visible and the capacity of wound healing gradually decrease [33-35]. These age-related changes may be due to a reduction in the function of adult stem cells, which exist in most tissues and are indispensible for normal tissue homeostasis, contributing to tissue repair and regeneration in response to damage [36-38].

Unlike UVB, UVA can penetrate into the lower dermis of skin and is largely involved in the photoaging mediated by oxidative stress [33-35]. Hydrogen peroxide is one of the reactive oxygen species (ROS) associated with UVA-induced cytotoxicity, as described previously $[39,40]$. Several previous reports have suggested that the protective effects of stem cells on various types of cells against UVA-induced ROS generation may be due to the secretion of specific cytokines from the stem cells. For instance, it has been reported that HGF has a protective effect on retinal pigment epithelium in oxidative injury [41]. In addition, a few reports have demonstrated that bFGF reduces the epithelial cell death induced by hydrogen peroxide [42] and IGF-1 reduces oxidative damages by glucose and nicotine in fibroblasts [43]. In this study, although the underlying mechanisms regarding the protective effects of hDSPC-CM against UVA-induced cell damages were not elucidated, we presume that hDSPC-CM, which resulted in a higher expression of such growth factors as
bFGF, IGF-1 and HGF (Fig. 1), may involve in cellular antioxidant pathways in the NHDFs and eventually inhibit the apoptotic cell death caused by UVA.

Wound healing is one of the most complex biological processes and requires a well-coordinated integration of cellular and molecular events of cell proliferation and migration, the redistribution of the extracellular matrix, angiogenesis, and tissue remodeling [44,45]. Among the various types of cells involved in the wound healing process, fibroblasts are among the most important: in particular, fibroblasts in the dermis surrounding a wound proliferate rapidly and migrate to the wound area $[44,45]$. After moving to the wound, fibroblasts begin to synthesize components of the extracellular matrix, such as collagen types I and III, which play a role in maintaining the integrity of the normal dermal environment. In this study, we found that hDSPCs specifically secreted higher levels of bFGF, IGFBP-1, IGFBP-2, HGF, VEGF and IGF-1 compared with non-hDSPCs (Fig. 1). Although we did not examine the effects of the identified growth factors on UVA-irradiated NHDFs, abundant supporting evidences suggest that these growth factors play important roles in the wound healing process. According to previous reports [46,47], such growth factors as FGF and IGF-1 enhance the proliferation of fibroblasts and contribute to increasing the production of collagen I in fibroblasts. In addition, IGFBP plays an important role in skin homeostasis, in regulating the IGF-mediated signaling of dermal cell migration, and in proliferation [48]. Therefore, we suggest that both the recovery of the collagen types I, IV, and V and TIMP1 mRNA expression levels, which were down-regulated by UVA irradiation (Fig. 2), and the increase of the migratory properties of UVA-irradiated NHDFs treated with hDSPC-CM (Fig. 3) may be due to the specific growth factors secreted from the hDSPCs. Further experiments are required to confirm the secreted factor that are responsible for the protective and restoring effects of hDSPC-CM on UVA-damaged fibroblasts.

Late apoptotic cells are usually defined as Annexin V/PI-double positive, whereas early apoptotic cells are Annexin V-positive and PI-negative. Interestingly, the hDSPC-CM-treated cells showed a significantly decreased percentage of UVA-induced early and late apoptotic cells compared with the non-hDSPC-CM-treated cells (Fig. 4). Herein, we demonstrated that hDSPC-CM may possess the ability to enhance dermal fibroblast viability and proliferation after UVA irradiation. This enhanced viability and proliferation may be also due to the increased release of paracrine mediators, such as bFGF, IGFBP-1, IGFBP-2, HGF, VEGF and IGF-1, from hDSPCs compared with non-hDSPCs.

In conclusion, we suggest that hDSPC-CM ameliorated the UVA-induced damage of NHDFs in a paracrine fashion and that hDSPC-CM, containing specific secretory factors, may have a promise for treating photo-damaged skin.

\section{Supporting Information}

Figure S1 hDSPG-GM had no effects on mRNA expressions of specific dermal makers in NHDFs. NHDFs were treated with either hDSPC-CM or non-hDSPC-CM for $24 \mathrm{hr}$. Total RNA was extracted, and real-time RT-PCR was performed for $\operatorname{COLlAl}(\mathrm{A}), \operatorname{COL} 4 \mathrm{Al}(\mathrm{B}), \operatorname{COL} 5 \mathrm{Al}(\mathrm{C}), \operatorname{MMPl}(\mathrm{D})$, and TIMP1(E). The graphs are shown as the means with error bars indicating S.D. of three independent experiments.

(TIF)

Figure S2 hDSPG-GM had no effects on the migration and proliferation of NHDFs. Effects of hDSPC-CM on NHDF migration. Scratch wound healing assays were performed using conditioned media for $48 \mathrm{hr}$. Images were obtained at 0, 24, 
and $48 \mathrm{hr}(\mathrm{A})$. The proliferation of the NHDFs was examined in the presence or absence of hDSPG-CM or non-hDSPG-CM (B). The graphs are shown as the means with error bars indicating S.D. of three independent experiments.

(TIF)

Figure S3 hDSPG-GM had no effects on cell death. NHDFs were incubated with either hDSPC-CM or non-hDSPC$\mathrm{CM}$ for $24 \mathrm{hr}$ and labeled with Annexin V-FITC and propidium iodide (PI). The distribution of apoptotic cells was analyzed using FACSAria II instrumentation. Only PI positive cells are dead (Q1). Cells showing Annexin V and PI double-labeling represent the stage of late apoptosis (Q2). Live cells were not labeled with Annexin V and PI (Q3), whereas Annexin V-labeled cells (Q4) represent the early stage of apoptosis. Ten thousand cells were analyzed for each condition. Control cells (A), cells treated with non hDSPG-CM (B), and cells treated with hDSPC-CM $(\mathrm{C})$ are shown. The data are representative of three independent experiments.

(TIF)

Figure S4 hDSPG-GM reduced the level of $\mathrm{H}_{2} \mathrm{O}_{2}$ immediately after the treatment. Fluorescence signals from Amplex

\section{References}

1. Weissman IL (2000) Stem cells: units of development, units of regeneration, and units in evolution. Cell 100: 157-168.

2. Weissman IL, Anderson DJ, Gage F (2011) Stem and progenitor cells: origins, phenotypes, lineage commitments, and transdifferentiations.Annu Rev Cell Dev Biol 17: 387-403.

3. Pittenger MF, Mackay AM, Beck SC, Jaiswal RK, Douglas R, et al. (1999) Multilineage potential of human mesenchymal stem cells. Science 284: 143-147.

4. Jiang Y, Jahagirdar BN, Reinhardt RL, Schwartz RE, Keene CD, et al. (2002) Pluripotency of mesenchymal stem cells derived from adult marrow. Nature 418: 41-49.

5. Prockop DJ (1997) Marrow stromal cells as stem cells for nonhematopoietic tissues. Science 276: 71-74.

6. Erices A, Conget P, Minguell JJ (2000) Mesenchymal progenitor cells in human umbilical cord blood. Br J Haematol 109: 235-242.

7. Zuk PA, Zhu M, Mizuno H, Huag J, Futrell JW, et al. (2001) Multilineage cells from human adipose tissue: implications for cell-based therapies. Tissue Eng 7: 211-218.

8. Zuk PA, Zhu M, Ashjian P, De Ugarte DA, Huang JI, et al. (2002) Human adipose tissue is a source of multipotent stem cells. Mol Biol Cell 13: 4279-4295.

9. Mezey E, Key S, Vogelsang G, Szalayova I, Lange GD, et al. (2003) Transplanted bone marrow generates new neurons in human brains. Proc Natl Acad Sci USA 100: 1364-1369.

10. Phinney DG, Prockop DJ (2007) Concise review: mesenchymal stem/ multipotent stromal cells: the state of transdifferentiation and modes of tissue repair - current views. Stem Cells 25: 2896-2902.

11. Toma JG, Akhavan M, Fernandes KJ, Barnabé-Heider F, Sadikot A, et al. (2001) Isolation of multipotent adult stem cells from the dermis of mammalian skin. Nat Cell Biol 3: 778-784.

12. Toma JG, McKenzie IA, Bagli D, Miller FD (2005) Isolation and characterization of multipotent skin-derived progenitors from human skin. Stem Cells 23: 727-737.

13. Bartsch G, Yoo JJ, De Coppi P, Siddiqui MM, Schuch G, et al. (2005) Propagation, expansion, and multilineage differentiation of human somatic stem cells from dermal progenitors. Stem Cells Dev 14: 337-348.

14. McKenzie IA, Biernaskie J, Toma JG, Midha R, Miller FD (2006) Skin-derived progenitors generate myelinating Schwann cells for the injured and dysmyelinated nervous system. J Neurosci 26: 6651-6660.

15. Crigler L, Kazhanie A, Yoon TJ, Zakhari J, Anders J, et al. (2007) Isolation of a mesenchymal cell population from murine dermis that contains progenitors of multiple cell lineages. FASEB J 21: 2050-2063.

16. Chen FG, Zhang WJ, Bi D, Liu W, Wei X, et al. (2007) Clonal analysis of nestin( $(-)$ vimentin(+) multipotent fibroblasts isolated from human dermis. J Cell Sci 120: 2875-2883.

17. Lorenz K, Sicker M, Schmelzer E, Rupf T, Salvetter J, et al. (2008) Multilineage differentiation potential of human dermal skin-derived fibroblasts. Exp Dermatol 17: 925

18. Biernaskie J, Paris M, Morozova O, Fagan BM, Marra M, et al. (2009) SKPs derive from hair follicle progenitors and exhibit properties of adult dermal stem cells. Cell Stem Cell 5: 610-623.

19. Driskell RR, Giangreco A, Jensen KB, Mulder KW, Watt FM (2009) Sox2positive dermal papilla cells specify hair follicle type in mammalian epidermis. Development 7136: 2815-2823.
Red assays, which are used to detect $\mathrm{H}_{2} \mathrm{O}_{2}$, in the presence or absence of UVA irradiation using assay buffer or conditioned media from either non-hDSPGs or hDSPGs (A, B) Absorption spectra after irradiation for $0 \mathrm{~min}(\mathrm{~A}, \mathrm{~B})$ and $10 \mathrm{~min}(\mathrm{C}, \mathrm{D})$. The graphs are shown as the mean \pm S.D. of three independent experiments. ${ }^{*} p<0.01$

(TIF)

\section{Table S1 Relative cytokine secretion analysis of hDSPG-CM. \\ (DOCX)}

\section{Acknowledgments}

We thank Mr. Hyoung-June Kim and Dr. Hyun Choi for technical support.

\section{Author Contributions}

Conceived and designed the experiments: JHS DWS. Performed the experiments: JHS JYP MGL. Analyzed the data: JHS DWS. Contributed reagents/materials/analysis tools: JHS. Wrote the paper: HHK TRL DWS.

20. Manini I, Gulino L, Gava B, Pierantozzi E, Curina C, et al. (2011) Multi-potent progenitors in freshly isolated and cultured human mesenchymal stem cells: a comparison between adipose and dermal tissue. Cell Tissue Res 344: 85-95.

21. Shim JH, Kang HH, Lee TR, Shin DW (2012) Enrichment and characterization of human dermal stem/progenitor cells using collagen type IV. J Dermatol Sci 67: 202-205.

22. Shim JH, Lee TR, Shin DW. Enrichment and characterization of human dermal stem/progenitor cells using intracellular granularity. Stem Cells and Develop. In press.

23. Sasaki M, Abe R, Fujita Y, Ando S, Inokuma D, et al. (2008) Mesenchymal stem cells are recruited into wounded skin and contribute to wound repair by transdifferentiation into multiple skin cell type. J Immunol. 180: 2581-2587.

24. Falanga V, Iwamoto S, Chartier M, Yufit T, Butmarc J, et al. (2007) Autologous bone marrow-derived cultured mesenchymal stem cells delivered in a fibrin spray accelerate healing in murine and human cutaneous wounds. Tissue Eng 13: 1299-1312.

25. Vojtassák J, Danisovic L, Kubes M, Bakos D, Jarábek L, et al. (2006) Autologous biograft and mesenchymal stem cells in treatment of the diabetic foot. Neuro Endocrinol Lett. Suppl 2: 134-137.

26. van Koppen A, Joles JA, van Balkom BW, Lim SK, de Kleijn D, et al. (2012) Human embryonic mesenchymal stem cell-derived conditioned medium rescues kidney function in rats with established chronic kidney disease. PLoS One. 7: e38746.

27. Iso Y, Spees JL, Serrano C, Bakondi B, Pochampally R, et al. (2007) Multipotent human stromal cells improve cardiac function after myocardial infarction in mice without long-term engraftment. Biochem Biophys Res Commun 354: 700706.

28. Chen L, Tredget EE, Wu PY, Wu Y (2008) Paracrine factors of mesenchymal stem cells recruit macrophages and endothelial lineage cells and enhance wound healing. PLoS One 3: e1886.

29. Kirkwood TB (2005) Understanding the odd science of aging. Cell 120: 437447.

30. Kirkwood TB (2005) Time of our lives. What controls the length of life? EMBO Rep 6: S4-8.

31. Dorshkind K, Montecino-Rodriguez E, Signer RA (2009) The ageing immune system: is it ever too old to become young again? Nat Rev Immunol 9: 57-62.

32. Dorshkind K, Swain S (2009) Age-associated declines in immune system development and function: causes, consequences, and reversal. Curr Opin Immunol 21: 404-407.

33. Gilchrest BA (1996) A review of skin ageing and its medical therapy. Br J Dermatol 135: 867-875.

34. Scharffetter-Kochanek K, Brenneisen P, Wenk J, Herrmann G, Ma W, et al. (2000) Photoaging of the skin from phenotype to mechanisms. Exp Gerontol 35: 307-316.

35. Yaar M, Gilchrest BA (2007) Photoageing: mechanism, prevention and therapy. Br J Dermatol 157: 874-887.

36. Rando TA (2006) Stem cells, ageing and the quest for immortality. Nature 441: 1080-1086.

37. Bell DR, Van Zant G (2004) Stem cells, aging, and cancer: inevitabilities and outcomes. Oncogene 23: 7290-7296.

38. Jones DL, Rando TA (2011) Emerging models and paradigms for stem cell ageing. Nat Cell Biol 13: 506-512. 
39. Zhang X, Rosenstein BS, Wang Y, Lebwohl M, Wei H (1997) Identification of possible reactive oxygen species involved in ultraviolet radiation-induced oxidative DNA damage. Free Radic Biol Med 23: 980-985.

40. Hazane-Puch F, Bonnet M, Valenti K, Schnebert S, Kurfurst R, et al. (2010) Study of fibroblast gene expression in response to oxidative stress induced by hydrogen peroxide or UVA with skin aging. Eur J Dermatol. 20: 308-320.

41. Shibuki H, Katai N, Kuroiwa S, Kurokawa T, Arai J, et al. (2002) Expression and neuroprotective effect of hepatocyte growth factor in retinal ischemiareperfusion injury. Invest Ophthalmol Vis Sci 43: 528-536.

42. Burdzińska A, Bartoszuk-Bruzzone U, Godlewski MM, Orzechowski A (2006) Sodium ascorbate and basic fibroblast growth factor protect muscle-derived cells from H2O2-induced oxidative stress. Comp Med 56: 493-501.

43. Rahman ZA, Soory M (2006) Antioxidant effects of glutathione and IGF in a hyperglycaemic cell culture model of fibroblasts: some actions of advanced glycaemic end products (AGE) and nicotine. Endocr Metab Immune Disord Drug Targets 6: 279-286.
44. Martin P (1997) Wound healing - aiming for perfect skin regeneration. Science 276: 75-81

45. Singer AJ, Clark RA (1999) Cutaneous wound healing. N Engl J Med 341: 738746.

46. Ionescu L, Byrne RN, van Haaften T, Vadivel A, Alphonse RS, et al. (2012) Stem cell conditioned medium improves acute lung injury in mice: in vivo evidence for stem cell paracrine action. Am J Physiol Lung Cell Mol Physiol 303: L967-977.

47. Burlacu A, Grigorescu G, Rosca AM, Preda MB, Simionescu M (2012) Factors Secreted by Mesenchymal Stem Cells and Endothelial Progenitor Cells Have Complementary Effects on Angiogenesis In Vitro. Stem Cells Dev. Oct 19.

48. Edmondson SR, Thumiger SP, Werther GA, Wraight CJ (2003) Epidermal homeostasis: the role of the growth hormone and insulin-like growth factor systems. Endocr Rev 24: 737-764. 